\title{
Association of Central Hypersomnia and Fatigue in Patients With Multiple Sclerosis
}

\section{A Polysomnographic Study}

\begin{abstract}
Anne-Laure Dubessy, MD, PhD, Sophie Tezenas du Montcel, MD, PhD, Frederique Viala, MD, Rana Assouad, MD, Michel Tiberge, MD, Caroline Papeix, MD, PhD, Catherine Lubetzki, MD, PhD, Michel Clanet, MD, PhD, Isabelle Arnulf, MD, PhD,* and Bruno Stankoff, MD, PhD*
\end{abstract}

Neurology ${ }^{\circledR}$ 2021;97:e23-e33. doi:10.1212/WNL.0000000000012120

\section{Abstract}

\section{Objective}

To evaluate sleepiness and central hypersomnia in multiple sclerosis (MS)-associated fatigue, we performed long-term polysomnography in patients with MS and healthy controls.

\section{Methods}

Patients with MS and healthy controls completed questionnaires on sleep, fatigue, sleepiness, and depression. They underwent nocturnal polysomnography, multiple sleep latency tests, and bed rest 24-hour polysomnography. Patients were divided into 3 groups (fatigue and sleepiness, fatigue and no sleepiness, neither fatigue nor sleepiness).

\section{Results}

Among 44 patients with MS, 19 (43.2\%) had fatigue and sleepiness, 15 (34\%) had only fatigue, and $10(22.7 \%)$ had neither fatigue nor sleepiness. Compared to 24 controls, patients with fatigue and sleepiness had higher REM sleep percentages (median [interquartile range] 20.5\% $[19.6-24.7]$ vs $18.1 \%[12.6-20.6])$, lower arousal indexes (12.7 [7.5-17.0] vs 22.4 [14.3-34.4]), and shorter daytime mean sleep latencies (8.6 [6.3-14.3] vs 16.6 [12.6-19.5] min). Restless leg syndrome, periodic leg movements, and sleep apnea had similar frequencies between groups. Central hypersomnia was found in $10(53 \%)$ patients with fatigue and sleepiness (narcolepsy type $2, \mathrm{n}=2)$, in $2(13 \%)$ patients with fatigue only, and in $3(30 \%)$ patients with neither fatigue nor sleepiness. Patients with central hypersomnia were younger and sleepier than those without hypersomnia, but had similar levels of fatigue, disability, depression, cognitive performance, and frequencies of the human leukocyte antigen $\mathrm{DQB1}{ }^{*} 0602$ genotype. The severity of fatigue increased with higher depression scores, higher sleepiness severity, and lower sleep efficacy.

\section{Conclusion}

Central hypersomnias are frequent in MS when fatigue and sleepiness are present. Screening them through polysomnography studies is recommended.
Correspondence Dr. Dubessy annelaure.dubessy@aphp.fr

\section{MORE ONLINE}

๑ CME Course

NPub.org/cmelist

*Isabelle Arnulf and Bruno Stankoff contributed equally to this work.

From the Neurology Department (A.-L.D., B.S.), Saint Antoine Hospital, AP-HP; Sleep Disorders Unit and National Reference Center for Narcolepsy and Hypersomnia (A.-L.D., I.A.), Department of Biostatistics (S.T.d.M.), and Neurology Department (R.A., C.P., C.L.), Pitié-Salpêtrière University Hospital, APHP, Paris; Neurology Department (F.V., M.C.) and Neurophysiology Department (M.T.), Purpan Hospital, Toulouse; and Institut du Cerveau et de la Moelle Épinière (C.L., I.A., B.S.), Sorbonne Université, Hôpital de la Pitié Salpêtrière, Inserm UMR S 1127, CNRS UMR 7225, Paris, France.

Go to Neurology.org/N for full disclosures. Funding information and disclosures deemed relevant by the authors, if any, are provided at the end of the article. 


\section{Glossary}

EDSS = Expanded Disability Status Scale ESS = Epworth Sleepiness Scale; HADRS = Hospital Anxiety and Depression Rating Scale; MFIS = Modified Fatigue Impact Scale; MS = multiple sclerosis; MSL = mean daytime sleep latency; MSLT = multiple sleep latency test; SOREMP = sleep onset in REM periods.

Fatigue is one of the most frequent symptoms in multiple sclerosis (MS), affecting up to $80 \%$ of patients, ${ }^{1}$ more than half of whom consider fatigue their most troublesome symptom. ${ }^{2}$ Fatigue affects employability, physical activity, and quality of life. ${ }^{3}$ It can be present early in the course of the disease, even prior to diagnosis, ${ }^{4}$ and may persist throughout the patient's life. The mechanisms of fatigue have not been completely elucidated. Some ${ }^{5,6}$ but not all $^{7}$ studies suggest that fatigue increases with disability and disease duration.

Fatigue may be the consequence of CNS dysfunction, thus defined as "primary fatigue." Secondary causes of fatigue include depression (both fatigue and depression being counteractable by exercise), ${ }^{8}$ adverse effects of medication, pain, nighttime voiding (which may in turn alter sleep quality), and disordered sleep. ${ }^{9}$ Sleep disorders in MS may consist of insomnia, restless leg syndrome (different from MS sensory discomfort) ${ }^{10-13}$ circadian sleep disorders, ${ }^{14}$ and rare hypersomnolence disorders (narcolepsy, central hypersomnia). ${ }^{10}$ Treating sleep disorders may reduce MS-related fatigue, ${ }^{15}$ supporting an intuitive hypothesis that they could trigger or at least worsen fatigue. Sleep apnea and periodic leg movements are incidentally observed in MS, ${ }^{16}$ but their clinical importance is debatable, in the absence of recorded symptoms and comparison against control groups. ${ }^{12}$ At disease onset, the frequency of sleep disorders appears similar among both patients with MS and healthy controls. ${ }^{17}$ Excessive daytime sleepiness is one of the major manifestations of sleep disorders. In MS, sleepiness without fatigue seems rare, ${ }^{18}$ suggesting that fatigue and sleepiness frequently overlap. However, it is unclear whether they have the same determinants and whether their intensities are correlated. ${ }^{6}$

One of the reasons why the role of sleep disorders in MS-related fatigue is not well defined is because they have not been systematically investigated, and rarely analyzed between patients with and without fatigue or alongside healthy controls. Notably, rare cases of symptomatic narcolepsy have been reported in patients with $\mathrm{MS}, 9,10$ but the prevalence of the association of these 2 diseases is unknown due to the lack of systematic screening for narcolepsy. In addition to narcolepsy, hypersomnias of central origin, including idiopathic and symptomatic hypersomnia, could be involved in MS-related fatigue. ${ }^{19}$ These rare disorders are characterized by impaired alertness despite normal or prolonged sleep. Their diagnosis is based on long, complex procedures, not previously performed in MS. ${ }^{19,20}$

In this present study, we aim at exploring whether sleep and central hypersomnolence disorders differ between patients with MS with fatigue and those without. We specifically hypothesize that only patients with sleepiness (rather than fatigue) would have a central hypersomnolence disorder. For this purpose, we recruited mildly disabled patients with MS with and without fatigue, dividing the former into 2 subgroups: those with fatigue and sleepiness vs those with fatigue but no sleepiness. We then systematically applied the procedures of hypersomnia diagnosis as well as nighttime and daytime bed-rest sleep monitoring during a 48-hour period. Healthy controls provided normative measures in the 48-hour sleep monitoring procedures.

\section{Methods}

\section{Standard Protocol Approvals, Registrations, and Patient Consents}

Participants signed written informed consent. The study received approval from the Ile de France-06 ethics committee and was registered on the clinicaltrials.gov database (NCT00137904).

\section{Participants}

Patients with MS were consecutively enrolled from the outpatient clinics in Pitié-Salpêtrière Hospital in Paris and Purpan Hospital in Toulouse, France, over a 33-month period from June 2003 to March 2006. Inclusion criteria were (1) diagnosis of MS with relapsing-remitting or primary progressive course, (2) age between 18 and 65, and (3) disability severity defined as a score $\leq 5.5$ on the Expanded Disability Status Scale (EDSS). ${ }^{21}$

To limit confounding factors, exclusion criteria included (1) active depression, ${ }^{22}(2)$ cognitive decline attested by a score $<136$ on the Mattis Dementia Rating Scale, ${ }^{23}$ (3) epilepsy, (4) obesity defined as a body mass index $>30 \mathrm{~kg} / \mathrm{m}^{2}$, and (5) use of cannabis. Treatment with antidepressants (including tricyclics, quadricyclics, and serotonin reuptake inhibitors), antihistamines, hypnotics, or benzodiazepines had to be discontinued 30 days before the sleep investigation, or for a period of at least 5 half-lives of the molecule. Patients unable to tolerate withdrawal were excluded from the study.

The original study was designed to compare polysomnographic features among patients with and without fatigue and sleepiness. Since comparison with healthy controls was relevant in order to interpret the 48-hour polysomnographic measurements, we further selected healthy controls recruited between January 2006 and June 2008 from the Pitié-Salpêtrière sleep disorders unit to generate a control group for 
parallel studies. All of the controls had previously received financial compensation for participating in the original study. All these control participants completed the same polysomnography and questionnaire procedures as the patient group. A total of 24 controls were selected from a group of 35 participants in order to create an age profile of the group similar to that of the MS group. Exclusion criteria for control participants included sleep complaints such as excessive daytime sleepiness (defined as an Epworth Sleepiness Scale [ESS] score $>10),{ }^{24}$ shift or night work, severe medical illness, chronic sleep deprivation, and use of medication known to modify sleep or wakefulness.

\section{Data Availability}

The data that support the findings of this study are available from the corresponding author upon reasonable request.

\section{Clinical Evaluation}

The ranking on the EDSS was determined by a neurologist. General cognitive functioning was assessed using the Mattis Dementia Rating Scale; working memory and attention were assessed using the Paced Auditory Serial Addition Test. ${ }^{25}$ The level of fatigue was assessed using the global Modified Fatigue Impact Scale (MFIS; 21 items, score range 0-84, scores increase with fatigue), ${ }^{26}$ a shortened part of the FrenchCanadian version of the Fatigue Impact Scale, ${ }^{27}$ which was validated and recommended by the MS Council for Clinical Practice Guidelines. Daytime sleepiness was measured using the ESS, a subjective questionnaire evaluating the propensity to fall asleep from 0 (none) to 3 (severe) in 8 everyday conditions. ${ }^{24}$ Patients and controls were interviewed by a psychiatrist to exclude participants with depression ${ }^{22}$ and they completed the Hospital Anxiety and Depression Rating Scale (HADRS). ${ }^{28}$

\section{Groups}

Patients with MS were sorted into 3 groups: patients with both fatigue and sleepiness, patients with fatigue but no sleepiness, and patients with neither fatigue nor sleepiness. They were classified as fatigued if (1) they declared fatigue to be one of the 3 main symptoms of their disease and had an MFIS score $\geq 45$ or (2) they considered fatigue to be the main symptom of their disease regardless of their MFIS score. Among the patients with fatigue, 2 subgroups were defined per the presence of sleepiness, according to an ESS score $>10$. Patients classified as "without fatigue" did not complain of fatigue and had an MFIS score $<45$. During the recruitment process, there were no patients with isolated excessive daytime sleepiness and no fatigue. Hence, this group was not created.

\section{Sleep Investigations}

Patients with MS and healthy controls underwent a face-toface interview to identify cataplexy, severe morning inertia, sleep paralysis, restorative naps, hypnagogic hallucinations, and restless leg syndrome. ${ }^{19}$ The diagnosis of central hypersomnia was performed through the following:
(1) Ruling out more common causes of excessive daytime sleepiness (insufficient sleep syndrome, sleep apnea syndrome, psychiatric hypersomnolence, long sleepers, circadian rhythm disorders, arousal disorders) by interview, sleep logs, and polysomnography; and

(2) Performing multiple sleep latency tests (MSLTs) followed by long-term sleep monitoring to document an abnormal daytime mean sleep latency (MSL) or a sleep excess. Abnormal MSL was defined as $<8$ minutes on MSLT, and sleep excess as a total sleep time $>11$ over 24 hours.

Participants were recommended to keep regular sleep routines 2 weeks prior to sleep study, allowing a minimum of $71 / 2$ hours of sleep time every day. Sleep monitoring lasted 48 hours, as previously described, ${ }^{20}$ and included the following:

1. An initial adaptation night from $23: 00$ to $6: 30$

2. Multiple sleep latency tests the following day, consisting of 5 nap opportunities at 8:00, 10:00, 12:00, 14:00, and 16:00, with each being interrupted after 20 minutes if no sleep occurred, and after 15 minutes asleep if sleep occurred

3. A second continuous sleep monitoring over the next 24 hours, allowing a determination of the 24-hour spontaneous sleep duration in relaxed, quiet conditions with participants allowed to sleep ad libitum (no interruption by the technicians, proposal to lie down and sleep in the morning and afternoon in the dark, as long as they could)

The sleep recordings included EEG, electro-oculograms, chin and bilateral tibialis anterior EMG, nasal pressure, respiratory efforts using thoracic and abdominal belts, ECG, position, tracheal sounds, pulse rate, and transcutaneous oximetry during the first night. Respiratory sensors were removed during the daytime test and the 24-hour sleep monitoring. The sleep stages, arousal, motor, and respiratory events were scored visually according to standard criteria. ${ }^{29}$ Sleep onset in REM periods (SOREMPs) were defined if REM sleep occurred within 15 minutes after sleep onset. The indexes of sleep fragmentation (arousal index, periodic leg movements, apnea-hypopnea index) and minimal oxygen saturation during sleep were measured during the first night. The human leucocyte antigen $\mathrm{DQB1} 1^{*} 0602$ genotype was investigated only in patients with MS, as it was mostly interesting in case of symptomatic narcolepsy.

Patients with abnormal polysomnography results meeting the diagnostic criteria for either narcolepsy or hypersomnia were classified as having "central hypersomnia on sleep tests." They were further subdivided into 2 distinct phenotypes:

1. Narcolepsy phenotype (MSL $<8$ minutes and $\geq 2$ SOREMPs, including sleep onset at nighttime)

2. Hypersomnia phenotype (total sleep time $>11[660$ minutes] over 24 hours during the long-term sleep monitoring or MSL $<8$ minutes and $<2$ SOREMPs, including sleep onset at nighttime) 


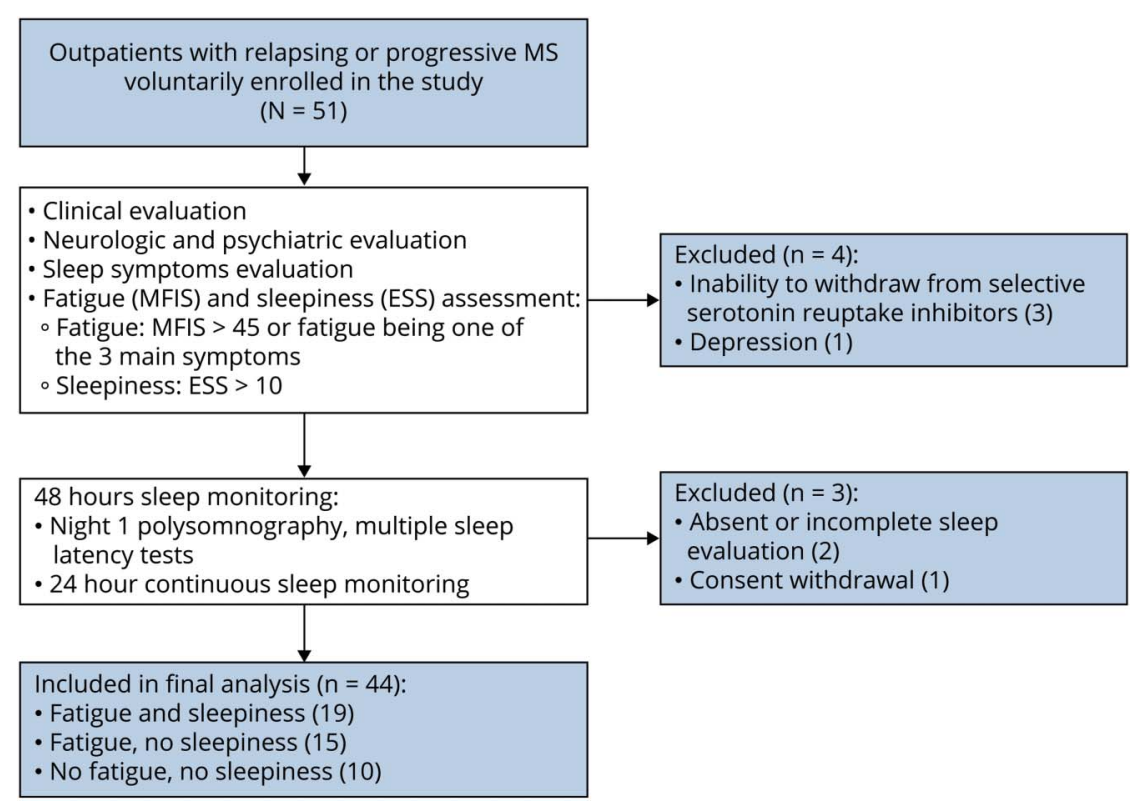

ESS = Epworth Sleepiness Scale; MFIS = Modified Fatigue Impact Scale; MS = multiple sclerosis.
Finally, patients who had both a central hypersomnia on sleep and a clinical complaint of sleepiness, with no better explanation for these findings, were classified as having a central disorder of hypersomnolence.

\section{Statistical Analysis}

The maximal value of MSL is 20 minutes, normative value is $15 \pm 5$ minutes, and MSL $<8$ minutes defines abnormal daytime sleepiness. ${ }^{30}$ A 5 -minute difference in

Table 1 Demographic and Clinical Characteristics of Patients With Multiple Sclerosis (MS) With and Without Fatigue

\begin{tabular}{|c|c|c|c|c|}
\hline Patients with MS & Fatigue and sleepiness & Fatigue and no sleepiness & Neither fatigue nor sleepiness & $p^{\mathrm{a}}$ \\
\hline Total & 19 & 15 & 10 & \\
\hline Age, y & $41.1(36.1-47.9)$ & $46.3(41.6-49.6)$ & $39.6(34.2-40.4)$ & 0.07 \\
\hline Sex, women & $15(79.0)$ & $11(73.3)$ & $2(20.0)^{b}$ & 0.005 \\
\hline Disease duration, y & $7.9(6.7-11.6)$ & $9.1(5.3-14.3)$ & $9.5(5.5-16)$ & 0.91 \\
\hline Relapsing form & $17(89)$ & $11(73)$ & $10(100)$ & 0.16 \\
\hline Expanded Disability Status Scale, 0-5.5 & $2.0(2.0-3.0)$ & $2.5(1.5-3.0)$ & $1.5(1.0-2.0)$ & 0.20 \\
\hline DMT at inclusion & $13(72.2)$ & $5(33.3)^{c}$ & $8(80)$ & 0.037 \\
\hline Mattis dementia score, 0-144 & $143(141-143)$ & $141(140-142)$ & $143(143-143)$ & 0.09 \\
\hline Paced Auditory Serial Addition Test, 0-60 & $48.0(43.0-53)$ & $48.0(38.0-53.5)$ & $48.0(44.5-52.0)$ & 0.78 \\
\hline MFIS, 0-84 & $56.0(46.0-63.0)$ & $55.0(49.0-57.0)$ & $20.5^{a}(16.5-35.8)$ & $<0.0001$ \\
\hline ESS, 0-24 & $14.0^{\mathrm{a}}(12.0-16.0)$ & $8.0(5.5-10.0)$ & $8.0(5.5-9.0)$ & $<0.0001$ \\
\hline HADRS-anxiety & $8.0(5.0-10.0)$ & $5.0(3.0-8.0)$ & $4.0(4.0-5.8)$ & 0.08 \\
\hline HADRS-depression & $6.0(3.0-7.0)$ & $6.0(4.5-7.5)$ & $1.0(0.3-3.5)^{\mathrm{a}}$ & 0.007 \\
\hline
\end{tabular}

Abbreviations: DMT = disease-modifying treatment; ESS = Expanded Disability Status Scale; HADRS = Hospital Anxiety and Depression Rating Scale; MFIS = Modified Fatigue Impact Scale.

Data are expressed as median (interquartile range) or $\mathrm{n}(\%)$

a $p$ for a difference among the 3 MS groups using Kruskal-Wallis test.

b $p<0.015$ for a post hoc difference with each other subgroup of patients.

${ }^{c} p$ did not reach significance for post hoc comparisons with other subgroups ( 0.08 and 0.04 for comparison with fatigue and sleepiness and no fatigue no sleepiness groups, respectively). 
MSL was therefore considered as clinically relevant and the sample size required to demonstrate this difference was calculated as previously shown in patients with MS with fatigue vs controls. ${ }^{31}$ Consequently, for a comparison among 3 MS groups, with power $80 \%$, the required number of patients per subgroup was equal to 16 .

Measures were expressed as the median (interquartile range) or $\mathrm{n}(\%)$, due to the reduced sample size. Kruskal-Wallis tests were used to compare quantitative measures between groups. For categorical measures, we used Fisher exact test. When the global significance was $<0.05$, pairwise comparisons were performed. To adjust for multiple comparisons,
Pearson correlations were performed using a significance $<0.005$. Analyses were performed using SAS version 9.3 (SAS Institute).

\section{Results}

\section{Characteristics of the Participants}

Fifty-one patients with MS took part in the study, 44 of whom were retained for final analysis. Seven patients were excluded for depression $(n=1)$, consent withdrawal $(n=$ 1 ), inability to withdraw from selective serotonin reuptake inhibitors before sleep investigations $(n=3)$, and absent or incomplete sleep measures $(n=2)$ (figure 1 ). Six

Table 2 Sleep Architecture in Patients With Multiple Sclerosis (MS) With and Without Fatigue and in Healthy Controls (HCs)

\begin{tabular}{|c|c|c|c|c|c|c|}
\hline & MS, pooled & $\begin{array}{l}\text { MS, fatigue, } \\
\text { sleepiness }\end{array}$ & $\begin{array}{l}\text { MS, fatigue, no } \\
\text { sleepiness }\end{array}$ & $\begin{array}{l}\text { MS, no fatigue, no } \\
\text { sleepiness }\end{array}$ & HCs & $\begin{array}{l}p \\
\text { Valuea }\end{array}$ \\
\hline Participants & 44 & 19 & 15 & 10 & 24 & \\
\hline Age, y & $\begin{array}{l}41.7 \\
(38.5-48.6)\end{array}$ & $41.7(34.1-48.2)$ & $46.3(40.7-46.3)$ & $39.6(33.5-40.5)$ & $\begin{array}{l}49.0 \\
(33.5-59.0)\end{array}$ & 0.12 \\
\hline Sex, women & $28(64)$ & $15(79)$ & $11(73)$ & $2(20)$ & $10(42)$ & 0.0043 \\
\hline Total sleep period, $\min$ & $477(442-511)$ & $477(449-521)$ & $472(413-513)$ & 478 (433-509) & $453(420-489)$ & 0.18 \\
\hline Sleep efficacy, \% & 87 (79-93) & $82(76-94)$ & $84(79-93)$ & $89(85-92)$ & $86(79-90)$ & 0.83 \\
\hline $\begin{array}{l}\text { Wakefulness after sleep onset, } \\
\text { min }\end{array}$ & $65(31-113)$ & $89(49-147)$ & $48(20-117)$ & $47(38-104)$ & $57(43-96)$ & 0.29 \\
\hline \multicolumn{7}{|l|}{ Latency to, min } \\
\hline Sleep onset & $19(8-41)$ & $21(2-42)$ & $27(17-55)$ & $13(8-15)$ & $27(14-38)$ & 0.12 \\
\hline REM sleep & $82(58-131)$ & $81(57-148)$ & $84(62-118)$ & $63^{b}(50-88)$ & $123(79-205)$ & 0.043 \\
\hline Total sleep time, $\min$ & 405 (366-453) & $404(363-464)$ & $405(325-430)$ & $407(388-470)$ & $394(349-417)$ & 0.42 \\
\hline \multicolumn{7}{|l|}{$\begin{array}{l}\text { Sleep stages, } \% \text { of total sleep } \\
\text { time }\end{array}$} \\
\hline N1 & $5.6(3.1-9.1)$ & $6.2(2.9-10.8)$ & $6.3(3.5-11.0)$ & $4.7(2.3-7.6)$ & $5.3(2.1-8.6)$ & 0.57 \\
\hline N2 & $\begin{array}{l}47.8 \\
(41.9-52.2)\end{array}$ & $47.8(42.0-54.2)$ & $43.1(40.0-50.3)$ & $49.6(46.3-52.8)$ & $\begin{array}{l}51.4 \\
(44.6-56.2)\end{array}$ & 0.17 \\
\hline N3 & $\begin{array}{l}23.3 \\
(18.8-29.4)\end{array}$ & $22.0(17.1-28.0)$ & $25.8(20.8-30.1)$ & $25.1(18.8-29.4)$ & $\begin{array}{l}24.6 \\
(21.6-30.2)\end{array}$ & 0.43 \\
\hline REM & $\begin{array}{l}21.4 \\
(19.4-25.4)\end{array}$ & $20.5^{a}(19.6-24.7)$ & $23.2(18.9-27.0)$ & $19.9(14.1-24.1)$ & $\begin{array}{l}18.1 \\
(12.6-20.6)\end{array}$ & 0.024 \\
\hline \multicolumn{7}{|l|}{ Sleep fragmentation, events/h } \\
\hline Arousal index & $\begin{array}{l}12.3 \\
(7.2-18.9)\end{array}$ & $12.7^{\mathrm{b}}(7.5-17.0)$ & $10.5^{\mathrm{b}}(4.4-18.8)$ & $12.5(6.8-22.5)$ & $\begin{array}{l}22.4 \\
(14.3-34.4)\end{array}$ & 0.0044 \\
\hline PLM index & $0.4(0.0-3.5)$ & $0.2(0-3.9)$ & $1.1(0-3.4)$ & $0.4(0.1-4.2)$ & $0.2(0.04-0.5)$ & 0.65 \\
\hline Apnea/hypopnea index & $1.1(0.4-4.2)$ & $1.4(0.3-3.0)$ & $1.0(0.3-4.9)$ & $3.5(0.5-8.0)$ & $3.1(1.2-9.5)$ & 0.13 \\
\hline Minimal $\mathrm{SaO}_{2}, \%$ & $92.0(89-93)$ & $91.0(89-93)$ & $91(87-94)$ & 92.5 (91.0-95) & $91.8(87-93)$ & 0.52 \\
\hline
\end{tabular}

Abbreviation: PLM = periodic leg movements.

Data are expressed as median (interquartile range) or $n(\%)$.

${ }^{a} p$ for a difference among the 3 MS subgroups and HCs using Kruskal-Wallis test (quantitative values) or $\chi^{2}$ test (categories).

${ }^{\mathrm{b}} p<0.0125$ for post hoc tests (Fisher exact test or Mann-Whitney) showing a difference with HCs. 
patients had primary progressive MS, whereas the remaining 38 had relapsing-remitting MS (table 1). Twenty-six patients were treated by disease-modifying therapies at inclusion (including 20 with interferons, 3 with glatiramer acetate, 2 with azathioprine, and 1 unspecified). Age and disease course were similar among the 3 MS subgroups, but the proportion of women was lower in the group without fatigue. Cognitive performances were within norms and similar among the groups. Patients with fatigue had higher depression symptoms than those without fatigue: HADRS depression scale scores (median, IQ range) were $6.0(3.0-7.0), 6.0(4.5-7.5)$, and 1.0 (0.3-3.5) for patients with both fatigue and sleepiness, fatigue but no sleepiness, and neither fatigue nor sleepiness, respectively $(p=0.007$ and $p<0.015$ for post hoc comparisons of patients with neither fatigue nor sleepiness vs the 2 other groups). The proportion of patients undergoing disease-modifying treatment tended to be lower among patients with fatigue but no sleepiness (table 1).
The healthy control group had a comparable mean age to the MS group. The proportion of women was lower compared to patients as a whole, but was in-between the values of the $3 \mathrm{MS}$ groups.

\section{Sleep and Sleepiness Measures}

The 4 groups differed in the latency and percentage of REM sleep as well as the arousal index (table 2). Compared to healthy controls, patients with fatigue and sleepiness had higher REM sleep percentages (median 20.5\% [interquartile range 19.6-24.7] vs $18.1 \%$ [12.6-20.6], $p=0.005)$ and lower arousal indexes (12.7 [7.5-17.0] vs 22.4 [14.3-34.4], $p=0.002)$. The MSL and percentage of participants with an abnormal MSL were also different amongst groups (table 3). In particular, patients with both fatigue and sleepiness had a shorter MSL (8.6 [6.3-14.3] minutes) than controls (16.6 [12.6-19.5] minutes, $p=0.0002$ ) and more frequently (42\% vs $9 \%)$ demonstrated abnormal ( $<8$ minutes) latencies. Notably, the apnea-hypopnea and periodic leg movement indexes were within normal values and not different among groups.

Table 3 Daytime Sleepiness Measures and 48 Hours Sleep Monitoring Among Patients With Multiple Sclerosis (MS) With and Without Fatigue and Healthy Controls (HCs)

\begin{tabular}{|c|c|c|c|c|c|c|}
\hline & MS, pooled & $\begin{array}{l}\text { MS, fatigue, } \\
\text { sleepiness }\end{array}$ & $\begin{array}{l}\text { MS, fatigue, no } \\
\text { sleepiness }\end{array}$ & $\begin{array}{l}\text { MS, no fatigue, no } \\
\text { sleepiness }\end{array}$ & HCs & $\begin{array}{l}p \\
\text { Value }^{\mathrm{a}}\end{array}$ \\
\hline Participants & 44 & 19 & 15 & 10 & 24 & \\
\hline \multicolumn{7}{|l|}{ Daytime MSLT } \\
\hline MSL, min & $\begin{array}{l}11.3 \\
(7.7-15.1)\end{array}$ & $8.6^{\mathrm{b}}(6.3-14.3)$ & $14.6(9.1-17.3)$ & $11.3(9.114 .5)$ & $\begin{array}{l}16.6 \\
(12.6-19.5)\end{array}$ & 0.0014 \\
\hline MSL less than 8 minutes & $12(27)$ & $8(42)$ & $2(13)$ & $2(20)$ & $2(9)$ & 0.049 \\
\hline 2 or more daytime SOREMPs & $6(14)$ & $4(21)$ & $1(7)$ & $1(10)$ & $0(0)$ & 0.07 \\
\hline Nighttime SOREMPs & $3(7)$ & $1(5)$ & $1(7)$ & $1(10)$ & $0(0)$ & 0,43 \\
\hline $\begin{array}{l}2 \text { or more night and daytime } \\
\text { SOREMPs }\end{array}$ & $6(14)$ & $4(21)$ & $1(7)$ & $1(10)$ & $0(0)$ & 0.07 \\
\hline \multicolumn{7}{|l|}{ Bed rest sleep monitoring } \\
\hline Total sleep time per 24 hours & $\begin{array}{l}552 \\
(461-624)\end{array}$ & $595(481-647)$ & $498(449-612)$ & $488(401-579)$ & $\begin{array}{l}504 \\
(444-567)\end{array}$ & 0.11 \\
\hline Total sleep time $>660$ minutes & $6(14)$ & $4(21)$ & $1(7)$ & $1(10)$ & $1(4)$ & 0.33 \\
\hline \multicolumn{7}{|l|}{ Final sleep disorder diagnosis } \\
\hline $\begin{array}{l}\text { Central hypersomnia on sleep } \\
\text { tests }\end{array}$ & $15(34)$ & $10(53)^{b}$ & $2(13)$ & $3(30)$ & $3(13)$ & 0.017 \\
\hline Narcolepsy phenotype & $3(7)$ & $2(11)$ & 0 & $1(10)$ & 0 & 0.14 \\
\hline Hypersomnia phenotype & $12(27)$ & $8(42)$ & $2(13)$ & $2(20)$ & $3(13)$ & 0.11 \\
\hline $\begin{array}{l}\text { Central disorder of } \\
\text { hypersomnolence }\end{array}$ & $10(23)$ & $10(53)$ & 0 & 0 & 0 & NA \\
\hline
\end{tabular}

Abbreviations: MSL = multiple sleep latency; MSLT = multiple sleep latency test; SOREMPs = sleep onset in REM periods.

Central hypersomnia on sleep tests: presence of narcolepsy (MSLT latency $<8$ minutes and SOREMPs $\geq 2$ ) or hypersomnia (MSLT latency $<8$ minutes and SOREMP $<2$ or total sleep time $>11$ hours during bed rest monitoring) phenotype in polysomnographic study, irrespective of clinical complaint. Central disorder of hypersomnolence: association of a complaint of daytime sleepiness and central hypersomnia on sleep tests. Data are expressed as median (interquartile range) or $\mathrm{n}(\%)$.

${ }^{a} p$ for a difference among the $3 \mathrm{MS}$ groups and HC using Kruskal-Wallis test (quantitative values) or Fisher exact test (categories).

${ }^{\mathrm{b}} p<0.0125$ for post hoc tests (Fisher exact test or Mann-Whitney) showing a difference with HCs. 
Table 4 Clinical Characteristics and Sleep Measures in Patients With Multiple Sclerosis (MS) With and Without Central Hypersomnia Phenotype on Sleep Tests

\begin{tabular}{|c|c|c|c|}
\hline & With central hypersomnia phenotype & Without central hypersomnia phenotype & $p$ Value \\
\hline Patients & 15 & 29 & \\
\hline Age, y & $39.0(32.0-43.6)$ & $42.7(39.7-49)$ & 0.02 \\
\hline Sex, women & $11(73.3)$ & $17(58.6)$ & 0.11 \\
\hline Body mass index, $\mathrm{kg} / \mathrm{m}^{2}$ & $23.1(20.0-24.4)$ & $23.4(20.4-25.3)$ & 0.76 \\
\hline \multicolumn{4}{|l|}{ MS characteristics } \\
\hline Age at MS onset, y & $26.6(24.2-35.4)$ & $33.2(27.9-41.1)$ & 0.08 \\
\hline Disease duration, $y$ & $9.1(7.3-11.6)$ & $7.9(5.1-16.2)$ & 0.81 \\
\hline Expanded Disability Status Scale, 0-5.5 & $2.0(1.5-2.0)$ & $2.0(1.0-3.0)$ & 0.31 \\
\hline Modified Fatigue Impact Scale, 0-76 & $54.0(36.0-63.5)$ & $52.0(38.0-57.0)$ & 0.40 \\
\hline \multicolumn{4}{|l|}{ Hospital Anxiety and Depression Rating Scale } \\
\hline Depression score, 0-21 & $3.0(1.0-7.5)$ & $5.0(3.0-7.0)$ & 0.35 \\
\hline Anxiety score, 0-21 & $6.0(4.5-10.0)$ & $5.0(3.0-9.0)$ & 0.36 \\
\hline \multicolumn{4}{|l|}{ Sleep symptoms } \\
\hline Sleepiness score, 0-24 & $12.0(10.0-15.5)$ & $10.0(7.0-11.0)$ & 0.04 \\
\hline Usual sleep time, $h$ & $8.0(7.0-9.0)$ & $8.0(7.0-8.0)$ & 0.94 \\
\hline Hallucination, \% & $0(0)$ & $0(0)$ & NA \\
\hline Sleep paralysis, \% & $0(0)$ & $0(0)$ & NA \\
\hline Cataplexy, \% & $0(0)$ & $0(0)$ & NA \\
\hline Restless legs syndrome & $0(0)$ & $3(9.7)$ & 0.61 \\
\hline HLA DQB1 $1^{a}$ 06:02 positive & $6(40)$ & $13(45)$ & 0.80 \\
\hline
\end{tabular}

Abbreviation: HLA = human leukocyte antigen.

Data are expressed as median (interquartile range) or $\mathrm{n}(\%)$

a $p$ for Kruskal-Wallis test (quantitative measures) or $\chi^{2}$ test (categories).

\section{Central Hypersomnia}

In the fatigue and sleepiness group, 10 (53\%) patients had a central disorder of hypersomnolence (defined as a complaint of daily sleepiness lasting for more than 3 months associated with abnormal MSL or abnormally long sleep time). This number included 2 with narcolepsy type 2 and 8 with a nonnarcoleptic, central hypersomnia (table 3). The other, nonsleepy MS and control subgroups had occasional abnormalities on the various tests, with narcolepsy-like or hypersomnialike phenotypes in $12 \%-30 \%$ of participants, but no complaint of sleepiness. Consequently, they did not meet the criteria of a sleep disorder. The 15 patients (regardless of the subgroup) with abnormal tests (abnormal MSL or abnormally long sleep time $/ 24$ hours) were younger and had higher sleepiness scores but no other difference compared to the 29 patients without hypersomnia (table 4). No patient had hypnagogic hallucination, sleep paralysis, or cataplexy. There was no difference in the frequency of human leukocyte antigen $\mathrm{DQB1}{ }^{*} 0602$ genotype between patients with and without central hypersomnia (table 4).

\section{Correlations Among Fatigue, Subjective Sleepiness, and Sleep Measures}

The severity of fatigue (measured by MFIS 1 ) increased with higher scores at the depression scale $(\mathrm{R}=0.55 ; p=0.0001)$, higher sleepiness score $(\mathrm{R}=0.42, p=0.005)$, and lower sleep efficacy $(\mathrm{R}$ $=-0.42 ; p=0.006$ ) (figure 2). Conversely, there was no significant correlation with nighttime sleep measures (including total sleep time per night and per 24 hours, arousal index, apnea-hypopnea index, or periodic leg movement index) or with MSL (table 5). There was no significant correlation between the sleepiness score (or the MSL) and MS markers, cognitive performance, psychological scores, or any sleep measures, including arousal, apneahypopnea, or periodic leg movement indexes (supplemental tables 1 and 2 at doi.org/10.5061/dryad.hqbzkh1dq).

\section{Discussion}

In this study, more than half of the patients complaining of fatigue and sleepiness were diagnosed with symptomatic 
Figure 2 Relationship Between Fatigue and Depression, Sleepiness and Sleep Efficacy

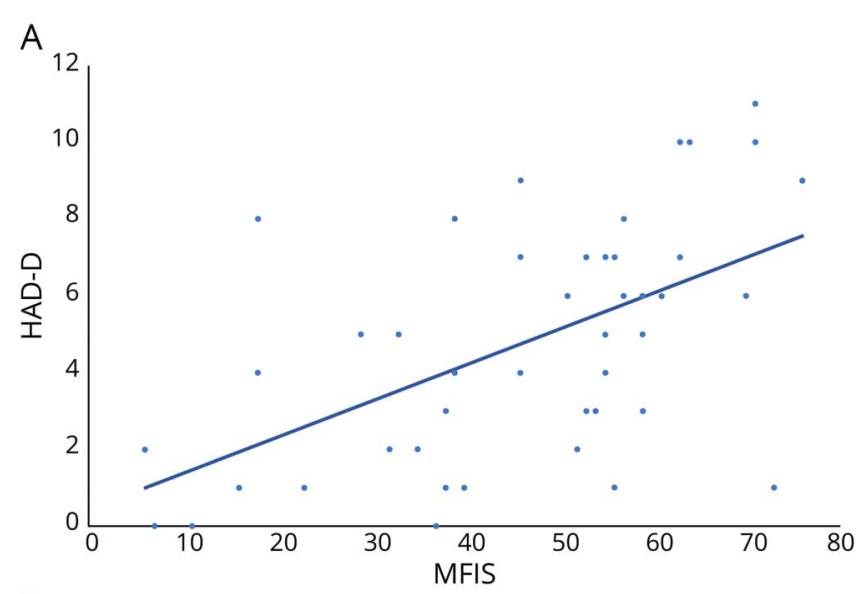

B

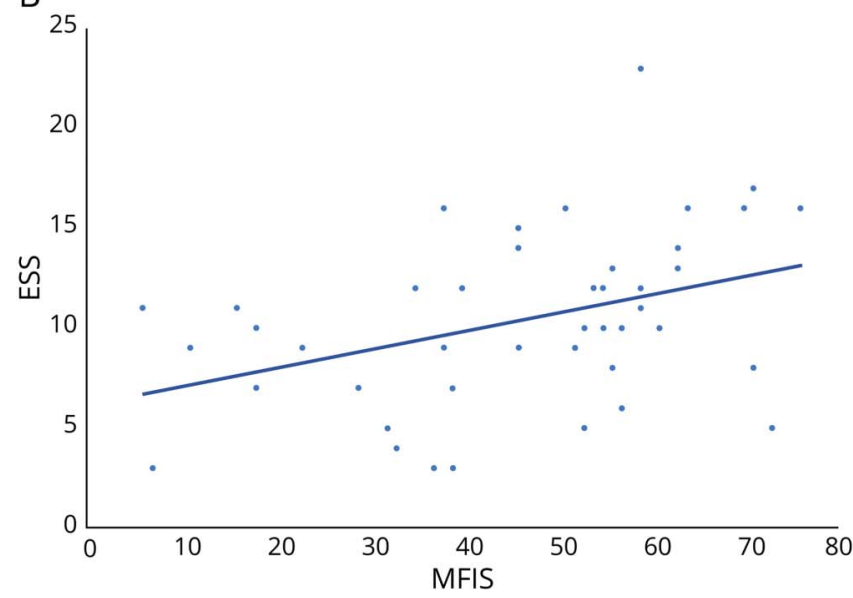

Correlation between fatigue scores on (A) the Modified Fatigue Impact Scale (MFIS) and depression subscore of the Hospital Anxiety and Depression Scale (HAD-D) $(R=0.55 ; p=0.0001)$ and $(B)$ scores on the Epworth Sleepiness Scale (ESS) $(R=0.42 ; R=0.005)$

narcoleptic or a non-narcoleptic central hypersomnia. This previously unknown finding advocates performing polysomnography, MSLT, and 24-hours bed rest sleep recording in patients with MS complaining of fatigue with sleepiness. In patients without sleepiness (i.e., only fatigue or neither one), sleep tests occasionally revealed hypersomnia phenotypes. Younger age and increased score on the ESS were the only predictors of central hypersomnia phenotypes in MS. Surprisingly, nocturnal sleep disturbances (including sleep fragmentation, restless leg syndrome, and sleep apnea) were just as frequent in patients with MS as healthy controls. Furthermore, they did not correlate with the level of fatigue or sleepiness, but just with sleep efficacy.

Central hypersomnias have been previously reported in patients with MS, mostly in case reports or small, uncontrolled series. ${ }^{9,10,32}$ In a published study, one-third of the 25 patients with MS and fatigue had short latencies on MSLT. ${ }^{6}$ However, most of them were treated with psychotropic drugs, ${ }^{6}$ which are known to affect sleep and sleepiness measurements. Compared to this study, we strictly excluded such drugs and this may explain differences in results. Among symptomatic narcolepsies, MS-associated narcolepsy ranks fourth in frequency after genetic disorders, tumors, and head trauma. ${ }^{33}$ Here, we found a higher than previously expected frequency of central hypersomnias (whether narcoleptic or not) in MS and explored their clinical indicators.

Several mechanisms may contribute to central hypersomnias among patients with MS. An increased susceptibility to autoimmune disorders could promote the co-occurrence of MS and narcolepsy type $2 .{ }^{34}$ The human leukocyte antigen DQB1*0602 (a marker of immune vulnerability to narcolepsy) was found in $43 \%$ of the patients, a frequency higher than the $18 \%$ reported in the French population. ${ }^{35}$ In our study, this antigen had a similar frequency in patients both with and without central hypersomnias. Moreover, the most frequent clinical phenotype identified was non-narcoleptic central hypersomnia (mostly characterized by short MSL and, to a lower extent, by sleep excess), which is not associated with any comorbid autoimmune disorders. ${ }^{34}$ These findings are in favor of central narcoleptic and non-narcoleptic hypersomnias being secondary to MS rather than an incidental co-occurrence. Indeed, MS lesions can directly alter the arousal systems (including hypocretin-1, histamine, noradrenalin, glutamate, and serotonin neurons). Narcolepsy type 1 is caused by a hypocretin-1 deficiency in the hypothalamus, but apart from a single case of narcolepsy symptomatic of an MS relapse with low CSF hypocretin-1 levels, CSF hypocretin-1 and histamine levels are normal in patients with MS with fatigue. ${ }^{33,36-38}$ Nonetheless, neuropathologic studies in MS have consistently identified lesions within the hypothalamus, as well as histaminergic neuronal loss or noradrenergic neuronal loss in the locus ceruleus. ${ }^{39,40}$ These findings and the various phenotypes observed in our study suggest that several arousal networks can be altered in MS, with a high heterogeneity among patients.

Previous studies suggested sleep disruption and other sleep disorders as potential causes of fatigue and sleepiness in MS. ${ }^{6,10,13,18}$ However, they were often conducted without control groups, despite sleep disorders being frequent in the general population. In contrast, the nocturnal sleep disturbances of our participants (including sleep fragmentation, restless leg syndrome, periodic leg movements, and sleeprelated breathing disorders) were as frequent in MS as in control groups, and did not correlate with the level of fatigue or sleepiness. Nonetheless, the level of fatigue increased as sleep efficacy decreased, suggesting that some symptoms (including nocturia, pain, spasticity, anxiety, and, as found in this study, depression $)^{6,10,13,18}$ unrelated to sleep disorders may prolong awakenings during the night and contribute to fatigue.

Fatigue and sleepiness partially overlapped in our patients, but MFIS and sleepiness scores correlated with distinct sleep measures. Sleepiness tended to correlate with a longer (and not a shorter) total sleep time, which is consistent with the hypothesis that sleepiness is caused by a central hypersomnia, 
Table 5 Comparisons Between Fatigue Severity and Multiple Sclerosis (MS) Markers, Cognitive Performance, Sleep, and Psychological Measures in the 44 Patients With MS

\begin{tabular}{|c|c|c|}
\hline \multirow[b]{2}{*}{ Measures } & \multicolumn{2}{|c|}{$\begin{array}{l}\text { Fatigue } \\
\text { (MFIS score) }\end{array}$} \\
\hline & $\mathbf{R}$ & $p$ Value \\
\hline \multicolumn{3}{|l|}{ Quantitative measures } \\
\hline Age, y & 0.26 & 0.09 \\
\hline Body mass index, $\mathrm{kg} / \mathrm{m}^{2}$ & -0.18 & 0.23 \\
\hline Disease markers & & ‘ \\
\hline Disease course, y & -0.04 & 0.82 \\
\hline Relapses in the last 2 years, $\mathbf{n}$ & -0.04 & 0.77 \\
\hline EDSS total score, 0-5.5 & 0.32 & 0.044 \\
\hline \multicolumn{3}{|l|}{ Cognition } \\
\hline Mattis scale, 0-144 & -0.37 & 0.02 \\
\hline Paced Auditory Serial Addition Test, 0-60 & -0.0877 & 0.57 \\
\hline \multicolumn{3}{|l|}{$\begin{array}{l}\text { Psychological scale (Hospital and } \\
\text { Depression Rating Scale) }\end{array}$} \\
\hline Anxiety score, 0-21 & 0.1981 & 0.20 \\
\hline Depression score, 0-21 & 0.55 & 0.0001 \\
\hline \multicolumn{3}{|l|}{ Daytime sleepiness measures } \\
\hline Epworth Sleepiness Score, 0-24 & 0.42 & 0.005 \\
\hline Daytime mean sleep latency, min & -0.0220 & 0.88 \\
\hline \multicolumn{3}{|l|}{ Nighttime sleep measures (night 2) } \\
\hline Sleep efficacy, \% & -0.41 & 0.006 \\
\hline Total sleep time, min & 0.07 & 0.66 \\
\hline N1 stage, $\%$ of total sleep time & -0.3269 & 0.03 \\
\hline N2 stage, \% of total sleep time & -0.08 & 0.56 \\
\hline N3 stage, $\%$ of total sleep time & -0.10 & 0.51 \\
\hline REM sleep, $\%$ of total sleep time & 0.19 & 0.22 \\
\hline Arousal index & 0.06 & 0.72 \\
\hline Apnea/hypopnea index & 0.07 & 0.63 \\
\hline Periodic leg movement index & 0.04 & 0.77 \\
\hline Total sleep time/24 hours, $\min$ & -0.02 & 0.88 \\
\hline \multicolumn{2}{|c|}{ Median (1st-3rd quartile) } & $p$ \\
\hline \multicolumn{3}{|l|}{ Categorical measures } \\
\hline Sex & & 0.05 \\
\hline 55 (39.5-59.5) & & \\
\hline $39(28.5-53.5)$ & & \\
\hline
\end{tabular}

Form of MS
Table 5 Comparisons Between Fatigue Severity and Multiple Sclerosis (MS) Markers, Cognitive Performance, Sleep, and Psychological Measures in the 44 Patients With MS (continued)

\begin{tabular}{lll}
\hline & Median (1st-3rd quartile) & $\boldsymbol{p}$ \\
\hline Progressive & $54(51.5-56.5)$ & 0.47 \\
\hline Remittent & $49(32.5-59)$ &
\end{tabular}

Abbreviations: EDSS $=$ Expanded Disability Status Scale; MFIS = Modified Fatigue Impact Scale.

Quantitative measures are correlated using Spearman correlation; categories (presented as median [1st-3rd quartiles]) are compared by KruskalWallis test. $p$ is considered as significant if lower than 0.005 .

rather than being the consequence of disrupted or shortened sleep. Disentangling specific factors underlying fatigue vs sleepiness in MS would require an additional group of patients with sleepiness but no fatigue. However, among the numerous patients screened for this study, none presented isolated sleepiness, which suggests that sleepiness contributes to fatigue rather than the opposite. The distinction between fatigue and sleepiness is particularly appropriate in the context of therapeutic strategies to alleviate fatigue and sleepiness. ${ }^{41,42}$ The wake-promoting agent modafinil has previously been ineffective against fatigue in patients with MS, except for those with high sleepiness scores, arguing for a differential effect on fatigue and sleepiness. ${ }^{42}$ Together with our findings, these results suggest that the score on the ESS would be an appropriate means to select patients for further therapeutic trials aiming at promoting alertness rather than targeting fatigue.

A major limitation of our study is the reduced size of the analyzed population, as fewer than 20 patients were evaluated per group. However, this is counterbalanced by the homogeneity of the population (absence of drugs, depression, mild motor disability) and the extended sleep protocols.

Central hypersomnias are frequent in MS in the context of sleepiness and fatigue, provided that they are investigated with long-term sleep monitoring. Better identification of patients with MS with excessive daytime sleepiness could lead to pharmacologic trials of stimulants focused on patients with central hypersomnias rather than fatigue.

\section{Acknowledgment}

The authors thank Christophe Sweet for editing this article for English language.

\section{Study Funding}

The study was funded by the ARSEP foundation (Association pour la Recherche sur la Sclérose en Plaques). INSERM (Institut National de la Santé et de la Recherche Médicale) was the study sponsor. 


\section{Disclosure}

The authors report no disclosures relevant to the manuscript. Go to Neurology.org/N for full disclosures.

\section{Publication History}

Received by Neurology March 17, 2020. Accepted in final form March 22, 2021.

\section{Appendix Authors}

\begin{tabular}{|c|c|c|}
\hline Name & Location & Contribution \\
\hline $\begin{array}{l}\text { Anne-Laure } \\
\text { Dubessy, MD, } \\
\text { PhD }\end{array}$ & $\begin{array}{l}\text { Neurology Department, } \\
\text { Saint Antoine Hospital, AP- } \\
\text { HP; Sleep Disorders Unit } \\
\text { and National Reference } \\
\text { Center for Narcolepsy and } \\
\text { Hypersomnia Pitié- } \\
\text { Salpêtrière University } \\
\text { Hospital, APHP, Paris, } \\
\text { France }\end{array}$ & $\begin{array}{l}\text { Collected the information } \\
\text { from medical files regarding } \\
\text { treatment, entered it in a } \\
\text { database and created the } \\
\text { tables, co-drafted the first } \\
\text { manuscript }\end{array}$ \\
\hline $\begin{array}{l}\text { Sophie } \\
\text { Tezenas du } \\
\text { Montcel, MD, } \\
\text { PhD }\end{array}$ & $\begin{array}{l}\text { Department of Biostatistics, } \\
\text { Pitié-Salpêtrière University } \\
\text { Hospital, APHP, Paris, } \\
\text { France }\end{array}$ & $\begin{array}{l}\text { Performed statistical } \\
\text { analysis }\end{array}$ \\
\hline $\begin{array}{l}\text { Frederique } \\
\text { Viala, MD }\end{array}$ & $\begin{array}{l}\text { Neurology Department, } \\
\text { Purpan Hospital, Toulouse, } \\
\text { France }\end{array}$ & $\begin{array}{l}\text { Diagnosed, recruited, and } \\
\text { evaluated the patients }\end{array}$ \\
\hline $\begin{array}{l}\text { Rana } \\
\text { Assouad, MD }\end{array}$ & $\begin{array}{l}\text { Neurology Department, } \\
\text { Pitié-Salpêtrière University } \\
\text { Hospital, APHP, Paris, } \\
\text { France }\end{array}$ & $\begin{array}{l}\text { Diagnosed, recruited, and } \\
\text { evaluated the patients }\end{array}$ \\
\hline $\begin{array}{l}\text { Michel } \\
\text { Tiberge, MD }\end{array}$ & $\begin{array}{l}\text { Neurophysiology } \\
\text { Department, Purpan } \\
\text { Hospital, Toulouse, France }\end{array}$ & Performed sleep analysis \\
\hline $\begin{array}{l}\text { Caroline } \\
\text { Papeix, MD }\end{array}$ & $\begin{array}{l}\text { Neurology Department, } \\
\text { Pitié-Salpêtrière University } \\
\text { Hospital, APHP, Paris, } \\
\text { France }\end{array}$ & $\begin{array}{l}\text { Diagnosed, recruited, and } \\
\text { evaluated the patients }\end{array}$ \\
\hline $\begin{array}{l}\text { Catherine } \\
\text { Lubetzki, MD, } \\
\text { PhD }\end{array}$ & $\begin{array}{l}\text { Neurology Department, } \\
\text { Pitié-Salpêtrière } \\
\text { University Hospital, APHP; } \\
\text { Sorbonne Universités, } \\
\text { Institut du Cerveau et de la } \\
\text { Moelle Épinière, ICM, } \\
\text { Hôpital de la Pitié } \\
\text { Salpêtrière, Inserm UMR S } \\
\text { 1127, CNRS UMR 7225, } \\
\text { Paris, France }\end{array}$ & $\begin{array}{l}\text { Diagnosed, recruited, and } \\
\text { evaluated the patients }\end{array}$ \\
\hline $\begin{array}{l}\text { Michel } \\
\text { Clanet, MD, } \\
\text { PhD, }\end{array}$ & $\begin{array}{l}\text { Neurology Department, } \\
\text { Purpan Hospital, Toulouse, } \\
\text { France }\end{array}$ & $\begin{array}{l}\text { Diagnosed, recruited, and } \\
\text { evaluated the patients }\end{array}$ \\
\hline $\begin{array}{l}\text { Isabelle } \\
\text { Arnulf, MD, } \\
\text { PhD }\end{array}$ & $\begin{array}{l}\text { Sleep Disorders Unit } \\
\text { and National Reference } \\
\text { Center for Narcolepsy and } \\
\text { Hypersomnia Pitié- } \\
\text { Salpêtrière University } \\
\text { Hospital, APHP; Sorbonne } \\
\text { Universités, Institut du } \\
\text { Cerveau et de la Moelle } \\
\text { Épinière, ICM, Hôpital de } \\
\text { la Pitié Salpêtrière, } \\
\text { Inserm UMR S 1127, } \\
\text { CNRS UMR 7225, Paris, } \\
\text { France }\end{array}$ & $\begin{array}{l}\text { Designed the study, } \\
\text { recruited the healthy } \\
\text { controls and obtained } \\
\text { funding for them, } \\
\text { performed sleep analysis, } \\
\text { co-drafted the first } \\
\text { manuscript }\end{array}$ \\
\hline
\end{tabular}

Appendix (continued)

\begin{tabular}{|c|c|c|}
\hline Name & Location & Contribution \\
\hline $\begin{array}{l}\text { Bruno } \\
\text { Stankoff, MD, } \\
\text { PhD }\end{array}$ & $\begin{array}{l}\text { Neurology Department, } \\
\text { Saint Antoine Hospital, AP- } \\
\text { HP; Sorbonne Universités, } \\
\text { Institut du Cerveau et de la } \\
\text { Moelle Épinière, ICM, } \\
\text { Hôpital de la Pitié } \\
\text { Salpêtrière, Inserm UMR S } \\
\text { 1127, CNRS UMR 7225, } \\
\text { Paris, France }\end{array}$ & $\begin{array}{l}\text { Designed the study, } \\
\text { obtained the grant for the } \\
\text { research program, } \\
\text { diagnosed, recruited and } \\
\text { evaluated the patients, co- } \\
\text { drafted the first manuscript }\end{array}$ \\
\hline
\end{tabular}

\section{References}

1. Minden SL, Frankel D, Hadden L, Perloff J, Srinath KP, Hoaglin DC. The Sonya Slifka Longitudinal multiple sclerosis study: methods and sample characteristics. Mult Scler J. 2006;12(1):24-38.

2. Fisk JD, Pontefract A, Ritvo PG, Archibald CJ, Murray TJ. The impact of fatigue on patients with multiple sclerosis. Can J Neurol Sci. 1994;21(1):9-14.

3. Janardhan V, Bakshi R. Quality of life in patients with multiple sclerosis. J Neurol Sci. 2002;205(1):51-58.

4. Berger JR, Pocoski J, Preblick R, Boklage S. Fatigue heralding multiple sclerosis. Mult Scler J. 2013;19(11):1526-1532.

5. Ghajarzadeh M, Jalilian R, Eskandari G, Sahraian MA, Azimi A, Mohammadifar M. Fatigue in multiple sclerosis: relationship with disease duration, physical disability, disease pattern, age and sex. Acta Neurol Belg. 2013;113(4):411-414.

6. Neau JP, Paquereau J, Auche V, et al.. Sleep disorders and multiple sclerosis: a clinical and polysomnography study. Eur Neurol. 2012;68(1):815.

7. Racke MK, Hawker K, Frohman EM. Fatigue in multiple sclerosis. Arch Neurol. 2004;61(2): 176.

8. Razazian N, Yavari Z, Farnia V, et al.. Exercising impacts on fatigue, depression, and paresthesia in female patients with multiple sclerosis. Med Sci Sports Exerc. 2016;48(5):796-803.

9. Veauthier C. Sleep disorders in multiple sclerosis: review. Curr Neurol Neurosci. 2015;15(5): 21.

10. Brass SD, Duquette P, Proulx-Therrien J, Auerbach S. Sleep disorders in patients with multiple sclerosis. Sleep Med Rev. 2009;14(2):121-129.

11. Mery V, Kimoff RJ, Suarez I, et al.. High false-positive rate of questionnaire-based restless legs syndrome diagnosis in multiple sclerosis. Sleep Med. 2015;16(7):877-882.

12. Gómez-Choco MJ, Iranzo A, Blanco Y, Graus F, Santamaria J, Saiz A. Prevalence of restless legs syndrome and REM sleep behavior disorder in multiple sclerosis. Mult Scler J. 2007;13(6):805-808

13. Veauthier C, Radbruch H, Gaede G, et al.. Fatigue in multiple sclerosis is closely related to sleep disorders: a polysomnographic cross-sectional study. Mult Scler. 2011, 17(5):613-622.

14. Melamud L, Golan D, Luboshitzky R, Lavi I, Miller A. Melatonin dysregulation, sleep disturbances and fatigue in multiple sclerosis. J Neurol Sci. 2011;314(1-2):37-40.

15. Veauthier C, Gaede G, Radbruch H, Gottschalk S, Wernecke K-D, Paul F. Treatment of sleep disorders may improve fatigue in multiple sclerosis. Clin Neurol Neurosurg. 2013;115(9):1826-1830.

16. Kaminska M, Kimoff R, Benedetti A, et al. Obstructive sleep apnea is associated with fatigue in multiple sclerosis. Mult Scler J. 2011;18(8):1159-1169.

17. Bahmani DS, Gerber M, Kalak N, et al. Mental toughness, sleep disturbances, and physical activity in patients with multiple sclerosis compared to healthy adolescents and young adults. Neuropsychiatr Dis Treat. 2016;12:1571-1579.

18. Attarian HP, Brown KM, Duntley SP, Carter JD, Cross AH. The relationship of sleep disturbances and fatigue in multiple sclerosis. Arch Neurol. 2004;61(4):525.

19. American Academy of Sleep Medicine. The International Classification of Sleep Disorders. 3rd ed. American Academy of Sleep Medicine; 2014.

20. Vernet C, Arnulf I. Idiopathic hypersomnia with and without long sleep time: a controlled series of 75 patients. Sleep. 2009;32(6):753-759.

21. Kurtzke JF. Rating neurologic impairment in multiple sclerosis: an expanded disability status scale (EDSS). Neurology. 1983;33(11):1444.

22. American Psychiatric Association. Diagnostic and Statistical Manual of Mental Disorders. 4th ed. American Psychiatric Association;2000.

23. Schmidt R, Freidl W, Fazekas F, et al. The Mattis Dementia Rating Scale: normative data from 1,001 healthy volunteers. Neurology. 1994;44(5):964.

24. Johns MW. A new method for measuring daytime sleepiness: the Epworth Sleepiness Scale. Sleep. 1991;14(6):540-545.

25. Gronwall DMA. Paced auditory serial-addition task: a measure of recovery from concussion. Percept Mot Skills. 1977;44(2):367-373.

26. Debouverie M, Pittion-Vouyovitch S, Louis S, Guillemin F. Validity of a French version of the fatigue impact scale in multiple sclerosis. Mult Scler J. 2007;13(8):1026-1032.

27. Fisk JD, Ritvo PG, Ross L, Haase DA, Marrie TJ, Schlech WF. Measuring the functional impact of fatigue: initial validation of the Fatigue Impact Scale. Clin Infect Dis. 1994;18(S1):S79-S83. 
28. Zigmond AS, Snaith RP. The Hospital Anxiety and Depression Scale. Acta Psychiatr Scand. 1983;67(6):361-370.

29. Iber C, Ancoli-Israel S, Chesson A, Quan SF. AASM Manual for the Scoring of Sleep and Associated Events: Rules, Terminology and Technical Specifications, 1st ed. American Academy of Sleep Medicine; 2007.

30. Carskadon MA, Dement WC, Mitler MM, Roth T, Westbrook PR, Keenan S. Guidelines for the Multiple Sleep Latency Test (MSLT): a standard measure of sleepiness. Sleep. 1986;9(4):519-524.

31. Taphoorn MJB, Someren E, Snoek FJ, et al. Fatigue, sleep disturbances and circadian rhythm in multiple sclerosis. J Neurol. 1993;240(7):446-448.

32. Kanbayashi $\mathrm{T}$, Shimohata $\mathrm{T}$, Nakashima I, et al. Symptomatic narcolepsy in patients with neuromyelitis optica and multiple sclerosis: new neurochemical and immunological implications. Arch Neurol. 2009;66(12):1563-1566.

33. Nishino S, Kanbayashi T. Symptomatic narcolepsy, cataplexy and hypersomnia, and their implications in the hypothalamic hypocretin/orexin system. Sleep Med Rev. 2005;9(4):269-310.

34. Barateau L, Lopez R, Arnulf I, et al. Comorbidity between central disorders of hypersomnolence and immune-based disorders. Neurology. 2016;88(1):93-100.

35. Tafti M, Hor H, Dauvilliers Y, et al. DQB1 locus alone explains most of the risk and protection in narcolepsy with cataplexy in Europe. Sleep. 2014;37(1): 19-25.
36. Knudsen S, Jennum P, Korsholm K, Sheikh S, Gammeltoft S, Frederiksen J. Normal levels of cerebrospinal fluid hypocretin-1 and daytime sleepiness during attacks of relapsing-remitting multiple sclerosis and monosymptomatic optic neuritis. Mult Scler J. 2008;14(6):734-738.

37. Bassetti C, Baumann CR, Dauvilliers Y, Croyal M, Robert P, Schwartz J-C. Cerebrospinal fluid histamine levels are decreased in patients with narcolepsy and excessive daytime sleepiness of other origin. J Sleep Res. 2010;19(4):620-623.

38. Constantinescu CS, Niepel G, Patterson M, et al. Orexin A (hypocretin-1) levels are not reduced while cocaine/amphetamine regulated transcript levels are increased in the cerebrospinal fluid of patients with multiple sclerosis: no correlation with fatigue and sleepiness. J Neurol Sci. 2011;307(1-2):127-131.

39. Polak PE, Kalinin S, Feinstein DL. Locus coeruleus damage and noradrenaline reductions in multiple sclerosis and experimental autoimmune encephalomyelitis. Brain J Neurol. 2011;134(3):665-677.

40. Barun B. Pathophysiological background and clinical characteristics of sleep disorders in multiple sclerosis. Clin Neurol Neurosurg. 2013;115(suppl 1):S82-S85.

41. Krupp LB, Coyle PK, Doscher C, et al. Fatigue therapy in multiple sclerosis: results of a double-blind, randomized, parallel trial of amantadine, pemoline, and placebo. Neurology. 1995;45(11):1956-1961.

42. Stankoff B, Waubant E, Confavreux C, et al. Modafinil for fatigue in MS: a randomized placebo-controlled double-blind study. Neurology. 2005;64(7):1139-1143. 


\section{Neurology}

\section{Association of Central Hypersomnia and Fatigue in Patients With Multiple Sclerosis: A Polysomnographic Study \\ Anne-Laure Dubessy, Sophie Tezenas du Montcel, Frederique Viala, et al. \\ Neurology 2021;97;e23-e33 Published Online before print April 30, 2021}

DOI 10.1212/WNL.0000000000012120

This information is current as of April 30, 2021

\section{Updated Information \&} Services

References

Citations

Subspecialty Collections

Permissions \& Licensing

Reprints including high resolution figures, can be found at: http://n.neurology.org/content/97/1/e23.full

This article cites 39 articles, 4 of which you can access for free at: http://n.neurology.org/content/97/1/e23.full\#ref-list-1

This article has been cited by 2 HighWire-hosted articles: http://n.neurology.org/content/97/1/e23.full\#\#otherarticles

This article, along with others on similar topics, appears in the following collection(s):

Multiple sclerosis

http://n.neurology.org/cgi/collection/multiple_sclerosis

Narcolepsy

http://n.neurology.org/cgi/collection/narcolepsy

Information about reproducing this article in parts (figures,tables) or in its entirety can be found online at:

http://www.neurology.org/about/about_the_journal\#permissions

Information about ordering reprints can be found online:

http://n.neurology.org/subscribers/advertise

Neurology $®$ is the official journal of the American Academy of Neurology. Published continuously since 1951, it is now a weekly with 48 issues per year. Copyright @ 2021 American Academy of Neurology. All rights reserved. Print ISSN: 0028-3878. Online ISSN: 1526-632X.

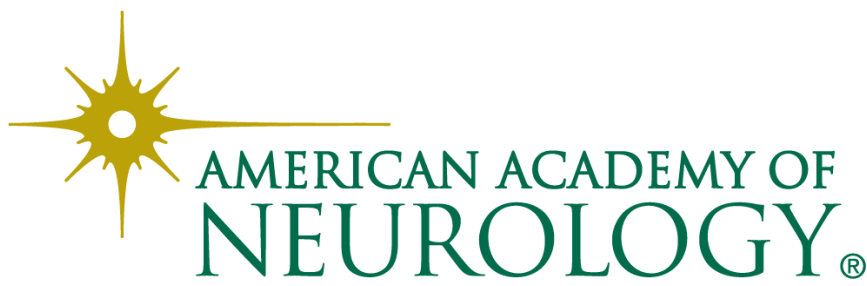

